\title{
BMJ Global Health Characteristics and effects of integrated nutrition and stimulation interventions to improve the nutritional status and development of children under 5 years of age: a systematic review and meta-analysis
}

Sophiya Dulal (D , ${ }^{1}$ Audrey Prost, ${ }^{2}$ Surendra Karki, ${ }^{3,4}$ Naomi Saville, ${ }^{2}$ Dafna Merom ${ }^{1}$

To cite: Dulal S, Prost A, Karki S, et al. Characteristics and effects of integrated nutrition and stimulation interventions to improve the nutritional status and development of children under 5 years of age: a systematic review and metaanalysis. BMJ Global Health 2021;6:e003872. doi:10.1136/ bmjgh-2020-003872

Handling editor Kerry Scott

- Additional supplemental material is published online only. To view, please visit the journal online (http://dx.doi.org/10. 1136/bmjgh-2020-003872)

Received 2 September 2020 Accepted 29 June 2021

Check for updates

C Author(s) (or their employer(s)) 2021. Re-use permitted under CC BY-NC. No commercial re-use. See rights and permissions. Published by BMJ.

For numbered affiliations see end of article.

\section{Correspondence to}

Ms Sophiya Dulal;

dulal.sophiya@gmail.com

\section{ABSTRACT}

Introduction Around 250 million children in low-income and middle-income countries are at risk of not fulfilling their developmental potential. There is a need to update syntheses investigating the effects of combined nutrition and stimulation interventions on children's growth and development and identify intervention characteristics associated with positive effects.

Methods We did a systematic review to: (1) understand the effects of integrated nutrition and stimulation interventions versus (i) usual care and (ii) standalone nutrition or stimulation interventions, on the growth and development of children under five; (2) explore intervention characteristics (delivery strategies, behaviour change techniques, intensity and personnel) associated with positive effects. We searched eight databases for studies published from inception to 16 November 2020. Eligible studies were randomised and non-randomised controlled trials of integrated nutrition and stimulation interventions examining growth and developmental outcomes. We performed meta-analyses for length-for-age/height-forage, weight-for-age and weight-for-length/weight-for-height Z scores and cognitive, motor and language development scores, and subgroup analyses by intervention characteristics. We conducted random-effects metaregression to assess potential subgroup differences in outcomes by intervention characteristics.

Results Twenty trials were included in the meta-analysis. Pooled effect sizes showed significant benefits of integrated interventions on developmental outcomes compared with usual care and standalone nutrition interventions $\left({ }^{P}>75 \%\right)$ but not on growth outcomes. Moreover, integrated interventions have non-significant effects on developmental outcomes compared with standalone stimulation interventions. Integrated interventions showed greater effects on cognitive $(p=0.039)$ and language $(p=0.040)$ outcomes for undernourished children compared with adequately nourished children. The effects of integrated interventions on developmental outcomes did not differ by intervention characteristics.

Conclusion Integrated interventions have greater benefits for children's development than usual care or standalone nutrition interventions, especially in settings with high levels of undernutrition. Future studies should use standardised reporting of implementation processes to identify intervention characteristics linked to positive effects.

\section{Key questions}

What is already known?

- Around 250 million children in low-income and middle-income countries are at risk of not meeting their full developmental potential.

- Previous systematic reviews have found strong evidence that benefits from stimulation interventions are maintained when given in combination with nutrition interventions.

What are the new findings?

- Integrated nutrition and stimulation interventions do not have positive effects on growth outcomes when compared with usual care or standalone nutrition interventions.

- Integrated interventions have non-significant effects on developmental outcomes compared with standalone stimulation interventions.

- Compared with usual care, integrated interventions have more positive effects on developmental outcomes for undernourished children than on adequately nourished children.

- We were unable to determine which characteristics of integrated interventions are associated with benefits for developmental outcomes.

What do the new findings imply?

- Implementation of integrated nutrition and stimulation interventions should be considered to benefit children's development, especially in settings with high levels of child undernutrition.

- Future research should map the characteristics of integrated nutrition and stimulation interventions following standardised guidelines to enable comparisons and understand which intervention characteristics influence effects.

\section{BACKGROUND}

An estimated 250 million children under 5 years of age in low/middle-income countries (LMICs) are at risk of poor development due to poverty, undernutrition and inadequate 
stimulation. ${ }^{1}$ These have adverse physical and psychosocial consequences that persist beyond childhood, perpetuating the intergenerational cycle of poverty. ${ }^{2}$ However, early exposure to nurturing care, including optimal nutrition and adequate stimulation (defined as 'sensory information received from interactions with people and environmental variability that engages a young child's attention and provides information, ${ }^{3}$ ) strongly influences children's development, protects them from the negative effects of adversities, and increases their opportunity to thrive. $^{1}$

Past research has primarily focused on understanding the effects of nutrition and stimulation interventions on children's growth and development when implemented separately. In a 2017 systematic review, Vaivada and colleagues investigated various nutrition-based approaches designed to improve child growth and developmental outcomes, including promotion of breastfeeding, iron supplementation, multiple micronutrient supplementation, complementary feeding education, supplementary feeding and therapeutic foods for acute malnutrition. ${ }^{4}$ These interventions were found to significantly improve growth, but their benefits for developmental outcomes were limited. ${ }^{4}$ Another systematic review reported a small effect of prenatal $(d=0.042)$ and postnatal $(d=0.076)$ nutrition interventions on children's cognitive development. ${ }^{5}$ In contrast, stimulation interventions $(\mathrm{n}=21)$ were found to be more beneficial for cognitive $(d=0.43)$ and language $(d=0.47)$ development than nutrition interventions $(\mathrm{n}=18, d=0.09)$ in children younger than 2 years. ${ }^{6}$ Furthermore, a recent review by Jeong $e t a l^{7}$ found that stimulation-based interventions have considerably larger effects on cognitive (standardised mean difference $[\mathrm{SMD}]=0.41$ ), motor $(\mathrm{SMD}=0.26)$, language $(\mathrm{SMD}=0.35)$ and socioemotional $(\mathrm{SMD}=0.24)$ development of children under 3 years in LMICs.

Recently, emphasis has been placed on implementing integrated nutrition and stimulation interventions as a more holistic approach to improving child growth and development and a more efficient use of resources. ${ }^{89} \mathrm{In}$ 2014, a systematic review by Grantham-McGregor et $a l^{10}$ concluded that there was no significant loss of effect on nutrition or developmental outcomes in children aged under 5 years when combining stimulation and nutrition interventions compared with single interventions, but little evidence of a synergistic interaction for child development. Meanwhile, two more recent systematic reviews and meta-analyses concluded that integrated interventions produce greater effects on developmental outcomes than nutrition intervention alone. ${ }^{3}{ }^{11}$ Several reviews have highlighted the need to identify characteristics of integrated interventions linked to positive effects. ${ }^{12-14}$ Understanding the characteristics of integrated interventions linked to benefits for child development is crucial to assist in the development of context-specific interventions, maximise their quality and support scale up. ${ }^{6712-14}$ Aboud and Yousafzai examined the association between three intervention characteristics (delivery strategy, contact hours, behaviour change techniques [BCTs]) and children's developmental outcomes for 21 stimulation interventions. ${ }^{6}$ However, existing reviews have not quantified the effects of intervention characteristics for integrated nutrition and stimulation interventions on both growth and developmental outcomes.

To address this research gap, we aimed to (1) systematically identify integrated community-based nutrition and stimulation interventions to improve growth and development among children under 5 years, and assess their quality; (2) describe the characteristics of these interventions using the Consolidated Advice on Reporting Early Childhood Development implementation research (CARE) framework ${ }^{15}$; (3) estimate, using meta-analyses, the effects of such integrated interventions on both growth and developmental outcomes among children under 5 years versus (i) usual care (referring to standard care or placebo) and (ii) standalone nutrition or stimulation interventions; (4) discuss any variations in effect and how these might relate to intervention characteristics.

\section{METHODS}

We conducted this systematic review following the 2009 Preferred Reporting Items for Systematic Reviews and Meta-Analysis (PRISMA) statement (online supplemental table 1). ${ }^{16}$ The review protocol was preregistered in PROSPERO (CRD42019131739).

\section{Search strategy}

We first conducted a top-up search, adding to the search conducted by Grantham-McGregor et al ${ }^{10}$ for studies published between January 2013 and September 2019 in Medline, PsycINFO, Cumulative Index of Nursing and Allied Health Literature (CINAHL), Embase, Global Health CABI Direct, The Cochrane Library, Academic Search Complete and Web of Science (online supplemental figure 1). We then re-ran the search for studies published from inception until 16 November 2020. Online supplemental table 2 shows key terms used in the search strategy. We searched the reference list of studies selected for full-text review.

\section{Inclusion and exclusion criteria}

We included studies carried out with children under 5 years and/or pregnant women. We included interventions that had both nutrition (micronutrient, macronutrient, food supplementation, or nutrition education) and stimulation (parent education, individual parent counselling, responsive care, or play) interventions versus any comparison arm/s (usual care, standalone nutrition or stimulation interventions). To assess the effects of integrated interventions on both growth and developmental outcomes, we included only studies reporting both anthropometric measures ( $Z$ scores for either length-for-age/height-for-age [LAZ/HAZ], weight-for-age [WAZ] or weight-for-length/weight-forheight [WLZ/WHZ]) and child development (either 
cognitive, motor or language development) outcomes. We included randomised controlled trials (RCTs) and non-randomised trials published in peer-reviewed journals and in English (see online supplemental table 3 for details).

\section{Study selection and data extraction Screening process}

All citations were imported into EndNote V.X9 for screening. Titles and abstracts were screened independently by one reviewer $(\mathrm{SD})$. Studies that did not meet the inclusion criteria were excluded. Two reviewers (SD and DM) retrieved and independently assessed the full text of potentially eligible studies. We resolved any disagreements over eligibility through discussion. Reasons for exclusions are reported using a PRISMA flow diagram. ${ }^{16}$

\section{Data extraction}

We used a standardised, prepiloted form to extract data on study characteristics. In addition, we extracted data related to intervention characteristics using the CARE guidelines to capture context, implementation strategy, intervention content, intensity, personnel, training and supervision, fidelity and compliance. ${ }^{15}$

\section{Quality appraisal}

We assessed the methodological quality of trials using the revised Cochrane for Risk of Bias 2 tool for RCTs and the Risk Of Bias in non-randomised studies of interventions tool for non-randomised trials. ${ }^{17}{ }^{18}$ Four reviewers (SD, AP, NS and $\mathrm{DM}$ ) assessed the quality of included studies in pairs and resolved any disagreements through discussion.

\section{Data synthesis and meta-analysis}

Two reviewers (SD and SK) independently extracted data for the meta-analysis. In studies with more than one outcome measurement time-point, we selected the measurement closest to the intervention's completion date. One study had two control groups; we combined data from these groups to enable a single pairwise comparison. ${ }^{19}$ One study reported fine and gross motor scores separately. ${ }^{20}$ We first calculated the means and standard deviations for fine and gross motor scores in each arm, then calculated a pooled ES for fine and gross motor scores for each arm. We sought additional information from the authors of nine studies where raw scores of growth or developmental outcomes were reported and received a response from three authors.

As studies used various measures of effect, we calculated Hedge's $g$ as the SMD between two groups of independent observations using the formula described by Higgins et al (2019). ${ }^{21}$ The ESs $0.2,0.5$ and 0.8 were considered 'small', 'moderate', and 'large' effects, respectively. We then synthesised quantitative data using pooled estimates and forest plots for each intervention type using random-effect models. We used random-effect models to adjust the study weights as heterogeneity was anticipated in the treatment effects due to variations in intervention context, content and intensity. Quantitative data were pooled and analysed together when at least two studies referred to similar interventions and outcomes.

We conducted two broad types of subgroup analyses. In the first, we examined the effects of integrated interventions vs usual care on outcomes according to the baseline nutritional status of children (undernourished and adequately nourished) and the components of nutrition interventions. In the second, we examined effects by delivery strategies (individual, group or both), the number of BCTs used to deliver the intervention (categorised as $<3$ or $\geq 3$ ), intervention intensity (duration of the entire intervention and the average number of interactions per month) and personnel (professionals, paraprofessionals, community volunteers, or volunteers and paraprofessionals together). All of these characteristics were prespecified in the review protocol. The proportion of variation in ESs due to heterogeneity was assessed by using the $I^{2}$ statistic, and values over $75 \%$ indicated a substantial level of heterogeneity. ${ }^{21}$ As an additional analysis not prespecified in the review protocol, we used random-effect metaregression to investigate subgroup differences in ESs. ${ }^{21}$ We did not test for subgroup differences if the overall ES was not significant. Publication bias was estimated using a funnel plot and the Egger test. ${ }^{21}$ All analyses were conducted in STATA V.16.1.

\section{Patient and public involvement}

Patients and the public were not involved in the design and conduct of this study.

\section{RESULTS}

\section{Search results}

The database search for studies published from inception to 16 November 2020 identified 28554 records. After removing duplicates, 20615 records were screened for titles and abstracts, which resulted in the exclusion of 20506 records. We reviewed full texts for the remaining 109 studies. Of those, 25 studies met the inclusion criteria (figure 1 and online supplemental table 4). Four additional studies that met the inclusion criteria were also identified by a forward/backward reference search. Out of 29 studies, four were follow-up studies of controlled trials, ${ }^{22-25}$ and one was a process evaluation of the same intervention, ${ }^{26}$ resulting in 24 unique studies.

\section{Risk-of-bias assessment}

Online supplemental figure 2 is the visual presentation of the review authors' judgement about the risk of bias domains for 24 unique trials: three trials were scored as low risk of bias, ${ }^{27-29} 16$ had some concerns, ${ }^{19} 2030-43$ and five were scored as being at high risk of bias. ${ }^{44-48}$

\section{Study characteristics}

Study characteristics are presented in table 1. Fifteen studies were cluster RCTs, ${ }^{20} 27-293133 \quad 3638-434647$ eight were individual RCTs, ${ }^{19} 30323537444548$ and one was a nonrandomised trial. ${ }^{34}$ Trials were conducted between 1978 and 2020 in 11 countries: Bangladesh (7), Jamaica (3), 


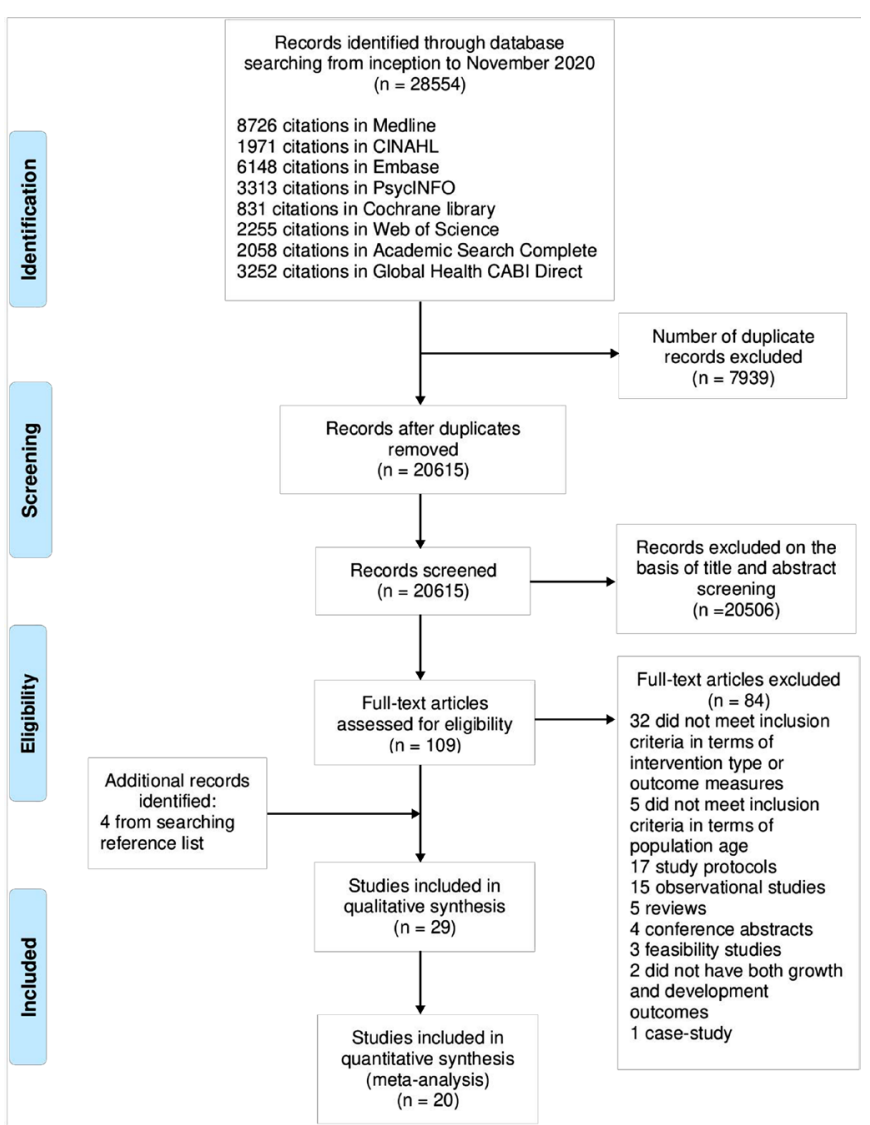

Figure 1 Preferred Reporting Items for Systematic Reviews and Meta-Analyses flow diagram describing the process of articles selection

Colombia (3), Uganda (2), Indonesia (2), Zambia, South Africa, Pakistan, Chile, India (2) and Madagascar. Sample sizes ranged from 110 to 3738 children, and all children were enrolled before 3 years of age, except in two studies where children up to 5 years were enrolled. ${ }^{37} 48$ Eleven of 24 trials tested interventions for children with poor nutritional status ${ }^{19} 28$ 30-35 374546 and four targeted children from the poorest population. ${ }^{20364244}$ The remaining trials were conducted in resource-limited rural ${ }^{272938-414347}$ or $\operatorname{urban}^{48}$ settings.

Thecomponents of nutritioninterventionincluded nutrition education $(\mathrm{n}=8),{ }^{27-293138394143}$ macronutrient supplementation (with/without education) $(\mathrm{n}=6),{ }^{19} 3342444548$ single or multiple micronutrient supplementation (with/ without education) $(\mathrm{n}=8)^{203234-36404647}$ and both macronutrient and micronutrient supplementation $(\mathrm{n}=2) .{ }^{30} 37$ In seven trials, stimulation was a new component integrated into existing nutritional services. ${ }^{20} 283133344047$ In two trials, the existing nutrition services were strengthened by adding new components such as micronutrient supplementation, new educational messages, enhancing health workers' counselling skills ${ }^{40}$ or intensive nutritional counselling services. ${ }^{20}$

Most stimulation interventions aimed to improve mother-child interactions by sharing information or teaching mothers/caregivers to communicate and play with their child. In 10 trials, the stimulation content was based on the Jamaican Reach up Programme, ${ }^{45}$ adapted to fit the local context. ${ }^{1920282931-3345-47}$ Two trials adapted the Care for Child Development curriculum by the World Health Organization and the United Nations Children's Fund, ${ }^{49}$ which included play and communication activities between a mother and a child. ${ }^{27}{ }^{40}$ Other trials focused on responsive parenting, including feeding and play activities ${ }^{3034-36383941-4448}$ and pre-school education. ${ }^{37}$ In addition to childcare, messages on maternal well-being, hygiene and sanitation were also imparted in three trials. ${ }^{39} 4143$ Only four trials explicitly mentioned their intervention/manual being guided by a theory of change or social learning theory/social cognitive learning theory. ${ }^{20} 394143$

In 12 trials, the comparison group received existing standard care, $192028293133343638-4043$ three trials provided placebo $^{32} 3748$ and six trials employed diverse activities including monitoring growth, health and feeding practices, ${ }^{27} 3546$ medical visits, ${ }^{45} 47$ and pre-school construction. ${ }^{41}$ Three trials did not provide details about the comparison group. ${ }^{304244}$

All trials used standard scales to measure developmental outcomes: 15 used the Bayley Scales of Infant Development (II and III), ${ }^{19} 282933-3638-434647$ four used the Griffiths Mental Development Scale. ${ }^{31} 324445$ Others used the INTERGROWTH-21st Neurodevelopment assessment tool, ${ }^{27}$ the Ages and Stages Questionnaire-3 (ASQ-3) and the Weschler Preschool and Primary Scale of Intelligence $-\mathrm{IV}{ }^{48}$ the Kaufman's Assessment Battery for Children $\mathrm{II}^{37}$ or the ASQ- $1 .{ }^{20}$ When obtained, measurements for height and weight were reported as $\mathrm{Z}$ scores, except in five trials which reported raw height and weight. ${ }^{31} 38444748$

\section{Implementation characteristics of integrated interventions}

We summarised the implementation characteristics of interventions in table 2 (see online supplemental table 5 for details).

Delivery strategy: In 13 of 24 trials, interventions were delivered individually to participants, either at home ${ }^{20} 3132353844-47$ or at a community centre or health clinic or preschool. ${ }^{19} 303748$ Three trials tested group sessions in the community ${ }^{3642}$ or a clinic, ${ }^{28}$ and seven trials combined both individual (home visit) and group sessions. ${ }^{2733} 34$ 39-41 43 One trial used both home visits and group sessions in two separate trial arms. ${ }^{29}$

BCTs: Three or more BCTs were used in 16 trials, ${ }^{19} 282931$ 33-36 38-43 4547 while only eight trials used one or two BCTs. ${ }^{20} 27303237444648$ The most widely used BCTs in all trials were information sharing and demonstration of play and communication activities to caregivers. Problem-solving strategies were employed in eight trials; these included identifying parenting issues, barriers to change, or problems with feeding and discussion of solutions. $^{20} 313536$ 39-41 43 Materials such as low-cost local or homemade toys and picture books were used in all but nine trials to facilitate caregivers practising play activities with their children. ${ }^{20} 273035-37394144$ Social support was 


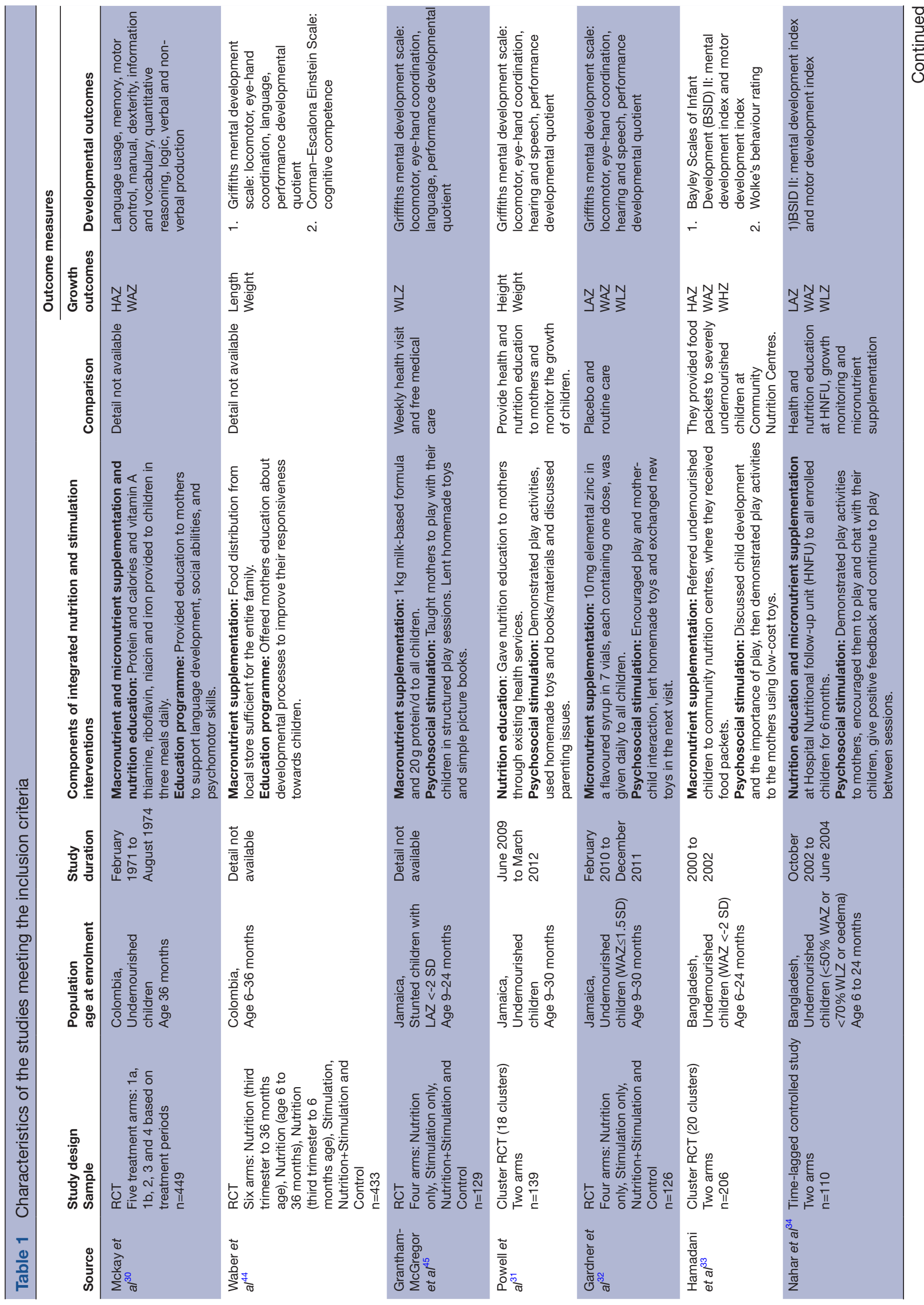

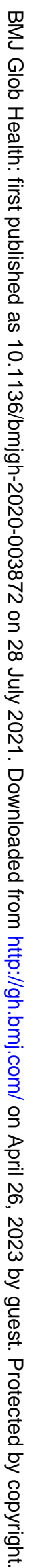




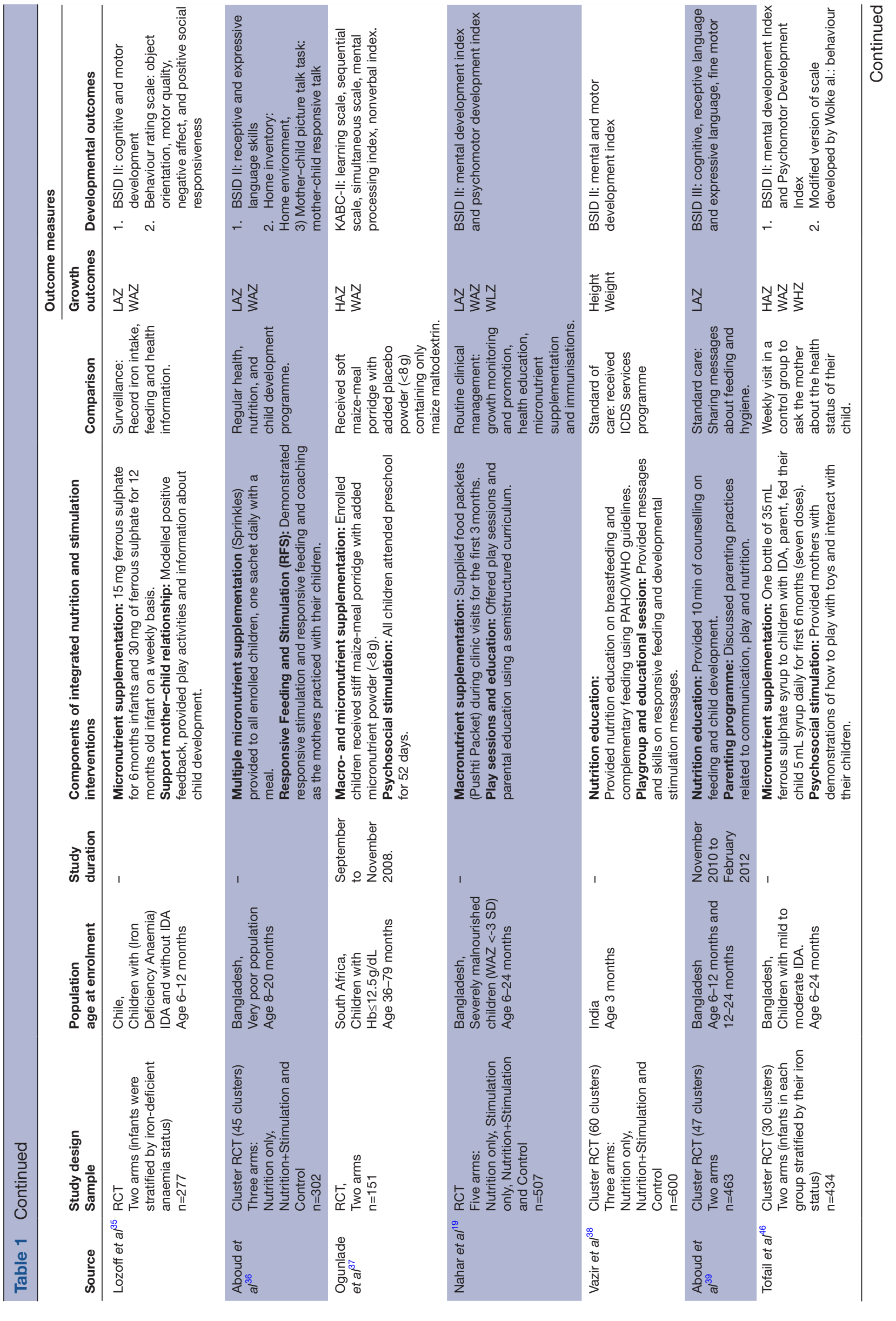




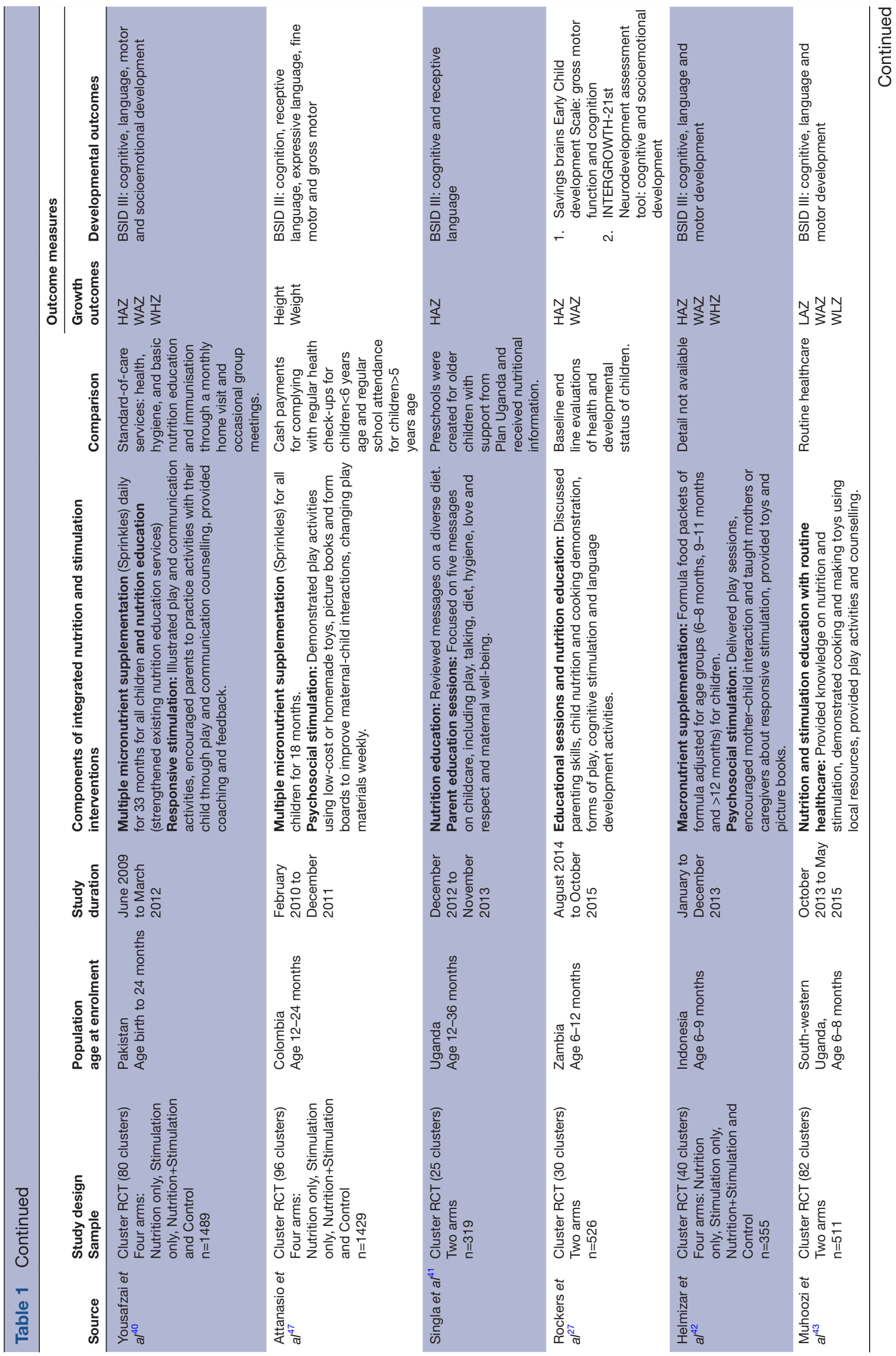




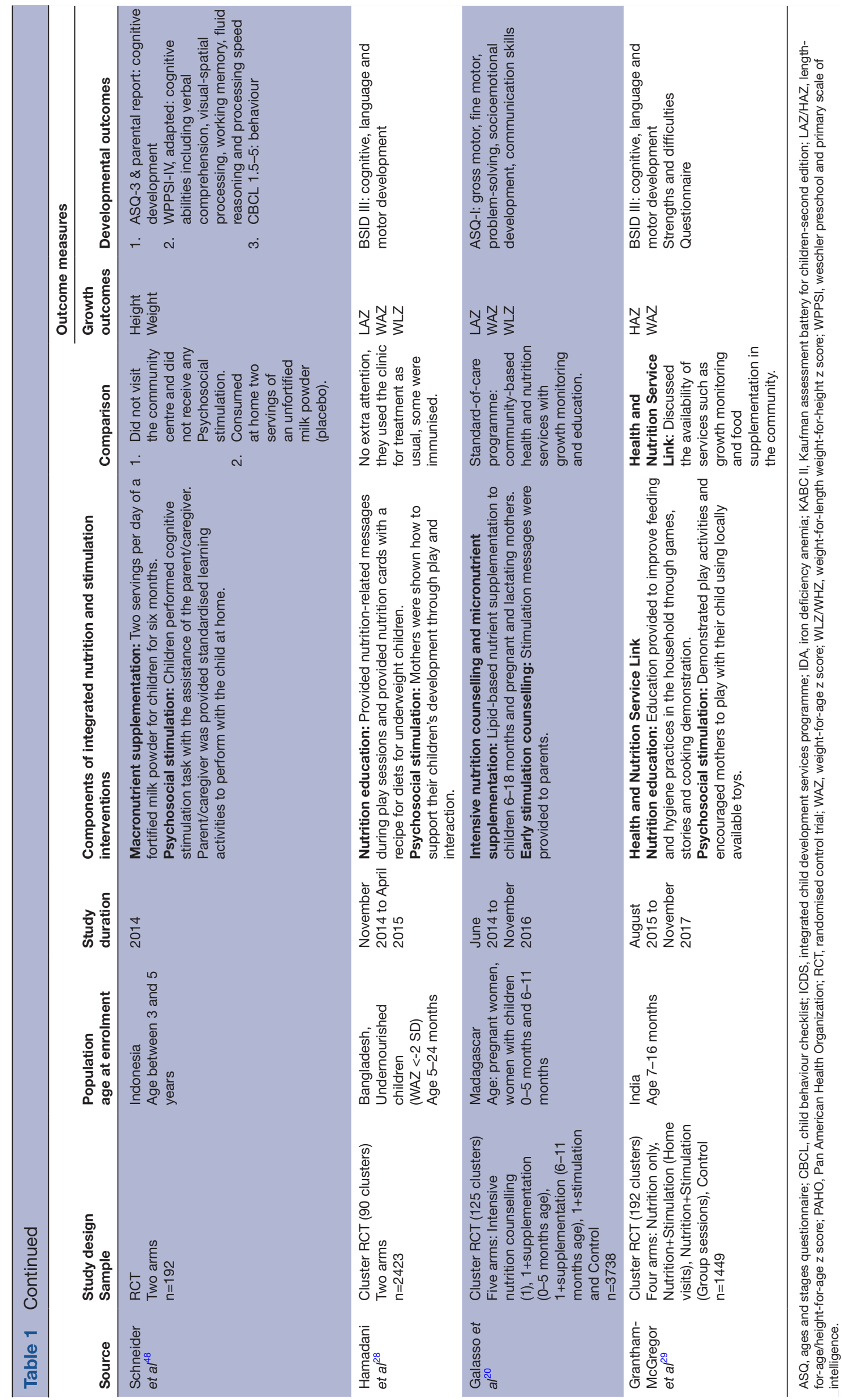




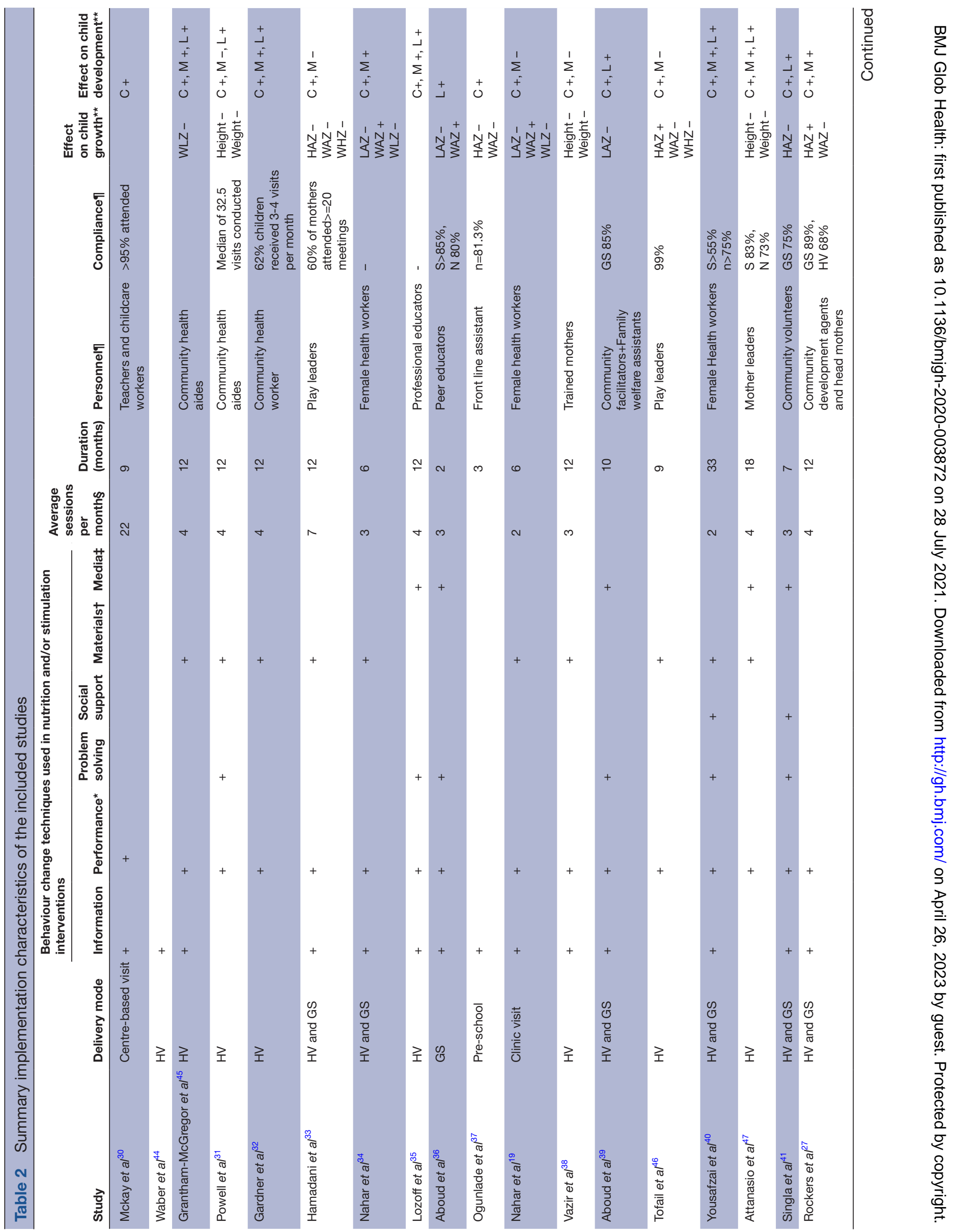




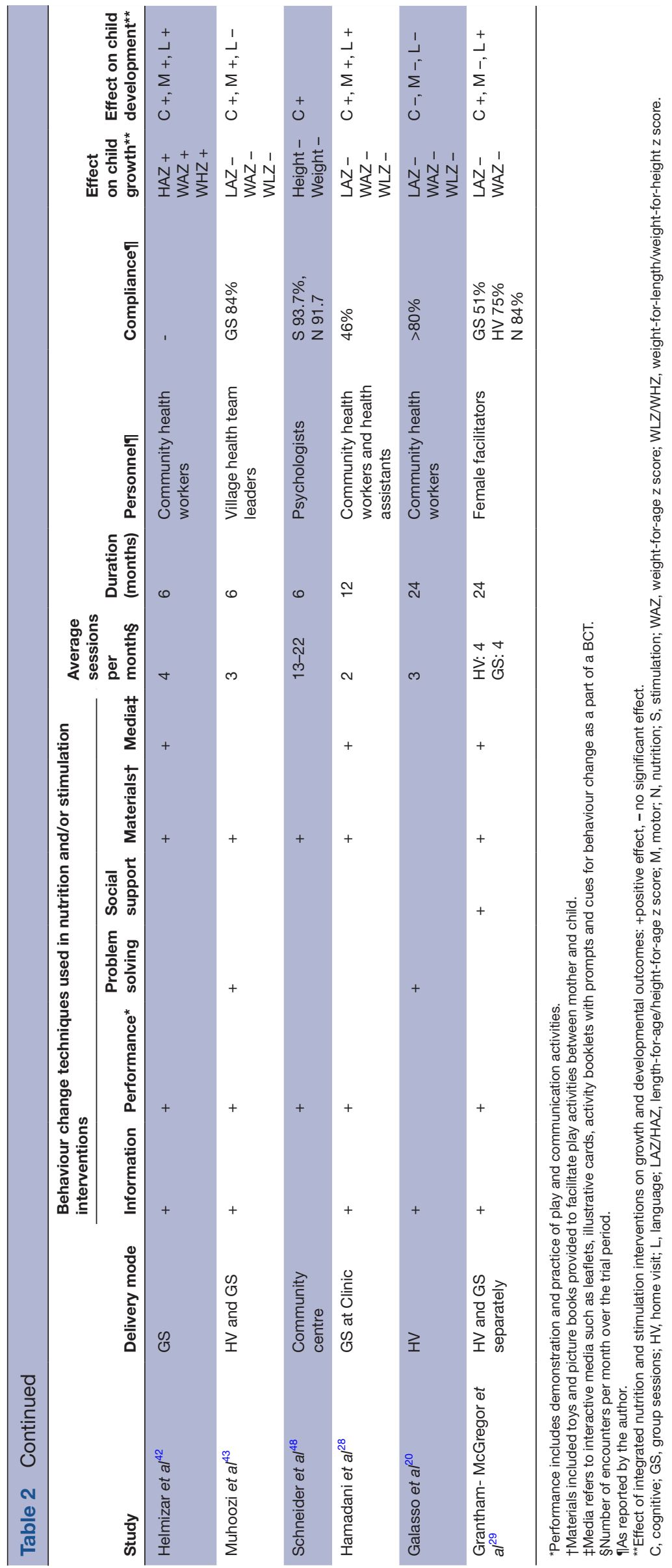

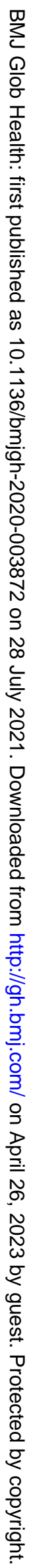


provided to mothers in only three trials so they could replicate play activities with their spouses and peers. ${ }^{29} 4041$ Eight trials used media such as written instructions, illustrative cards, activity booklets with prompts, and behaviour change cues. ${ }^{28} 29353639414247$

Intensity: In 11 trials, the duration of intervention was less than 12 months. ${ }^{19} 303436373941-434648$ Twelve trials tested interventions that lasted for 12 months or more. ${ }^{20} 27-2931-333538404547$ We calculated the average number of intended contact sessions (individual, group or both) per month (table 2). Out of 24 trials, the least intensive interventions involved monthly group sessions lasting 1 hour and $20 \mathrm{~min}$, along with $30 \mathrm{~min}$ individual sessions at participants' homes for 33 months. ${ }^{40}$ The most intensive intervention involved individual sessions at a community centre for 5 days per week, lasting for 6 hours a day over 9 months. ${ }^{30}$

Delivery personnel: Most interventions $(n=10)$ were delivered by paraprofessionals who were specially trained to provide health services, had 8-12 years of education and were paid. ${ }^{19} 202931323437404245$ Seven trials tested interventions delivered by trained community volunteers (women from local communities). ${ }^{33} 363841434647$ In four trials, interventions were delivered by professionals with relevant degrees, including psychologists, ${ }^{48}$ teachers, ${ }^{30}$ professional educators, ${ }^{35}$ and health assistants. ${ }^{28}$ Two trials included both volunteers and paraprofessionals. ${ }^{27} 39$

\section{Pooled ESS on growth and developmental outcomes}

A total of 24 trials met the review's inclusion criteria. Of these, 20 trials with 16568 participants were included in the meta-analysis. ${ }^{19} 20$ 27-34 36 38-43 45-47 We were unable to calculate ES for both growth and developmental outcomes for the four remaining trials due to insufficient/incompatible information such as reporting raw scores. ${ }^{35} 374448$ Seventeen trials tested integrated interventions vs usual care. ${ }^{19} 20$ 27-30 32 36 38-43 45-47 One trial had two arms with integrated interventions delivered using two different modes. ${ }^{29}$ Thirteen and eight trials, respectively, compared integrated versus standalone nutrition ${ }^{19} 202931-3438404245-47$ and stimulation interventions. ${ }^{19} 3236404245-47$ Five trials examined synergistic interactions between nutrition and stimulation interventions. ${ }^{1932404547}$

\section{Integrated interventions versus usual care}

Compared with usual care, integrated nutrition and stimulation interventions had a moderate positive effect on children's cognitive ( $\mathrm{n}=17$, ES $0.53,95 \%$ CI $0.30,0.75$, $I^{2}=96 \%$, $\left.\mathrm{p}<0.001\right)$, motor $(\mathrm{n}=14$, ES $0.30,95 \%$ CI0.08, $\left.0.51, I^{2}=94 \%, \mathrm{p}<0.001\right)$ and language $(\mathrm{n}=13$, ES 0.42 , $95 \%$ CI $0.16,0.68, I^{2}=96 \%, \mathrm{p}<0.001$ ) outcomes (online supplemental figure 3). We found non-significant effects of integrated interventions on growth outcomes. We conducted a sensitivity analysis excluding three trials with a high risk of bias, and found similar ESs, with high heterogeneity.
In order to explore possible reasons for the heterogeneity of intervention effects on developmental outcomes, we performed subgroup analyses by (1) baseline nutritional status of children and (2) components of nutrition intervention (online supplemental figure 4). In the subgroup analyses stratifying studies by nutritional status, heterogeneity within each subgroup remained high and significant $\left(I^{2}>75 \%, \mathrm{p}<0.001\right)$. The ESs for cognitive (mean ES diff $=0.49,95 \%$ CI $0.03,0.96, p=0.039$ ) and language (mean ES diff $=0.63,95 \%$ CI $0.03,1.23, \mathrm{p}=0.040$ ) outcomes were significantly greater among undernourished children compared with adequately nourished children. The effect on motor outcome was non-significant for the undernourished group. When disaggregating by three components of nutrition intervention, ES for macronutrient supplementation (with/without education) and stimulation interventions had a positive effect on cognitive (n=3, ES $0.77,95 \%$ CI $0.24,1.30, I^{2}=83 \%$, $\mathrm{p}=0.003)$ and motor $(\mathrm{n}=3$, ES $0.32,95 \%$ CI $0.01,0.63$, $\left.I^{2}=53 \%, \mathrm{p}=0.119\right)$ but not on language outcomes. Single or multiple micronutrient supplementation (with/ without education) and stimulation interventions had a moderate effect on cognitive ( $\mathrm{n}=5$, ES $0.24,95 \%$ CI $\left.0.04,0.44, I^{2}=83 \%, \mathrm{p}<0.001\right)$ and language $(\mathrm{n}=5$, ES $0.26,95 \%$ CI $0.004,0.51, I^{2}=90 \%, \mathrm{p}<0.001$ ) but not on motor outcomes. Nutrition education and stimulation interventions showed positive effects on all developmental outcomes (6-8 studies; ES range: 0.40 to $0.59, I^{2}$ $>75 \%)$. The subgroup differences in any developmental outcomes by nutrition components were not significant.

Funnel plots (online supplemental figure 5) suggest that publication bias is unlikely for both growth and developmental outcomes, as ESs from the published studies were roughly equally distributed around the mean, indicating a low risk of bias towards the larger ES. The Egger test provided no evidence of any publication bias on cognitive $(p=0.205)$, motor $(p=0.907)$, language $(p=0.949)$, $\mathrm{LAZ} / \mathrm{HAZ}(\mathrm{p}=0.635)$, and WLZ/WHZ $(\mathrm{p}=0.128)$ scores. However, there was a slight indication of publication bias in reporting of WAZ ( $\mathrm{p}=0.024)$ score.

\section{Integrated interventions versus single interventions}

Figures 2 and 3 include forest plots describing the effects of integrated interventions versus standalone nutrition and stimulation interventions on growth and developmental outcomes. Compared with the nutrition intervention only group, the pooled effect for the integrated interventions group indicated moderate effects for cognitive ( $\mathrm{n}=14$, ES $0.31,95 \%$ CI 0.19 to $\left.0.42, I^{2}=72 \%, \mathrm{p}<0.001\right)$ and language ( $\mathrm{n}=9$, ES $0.24,95 \%$ CI 0.09 to $0.40, I^{2}=82 \%$, $\mathrm{p}=<0.001)$ outcomes, small effects for motor outcome ( $\mathrm{n}=14$, ES $0.07,95 \%$ CI 0.008 to $0.14, I^{2}=20 \%, \mathrm{p}=0.240$ ); non-significant effects on WAZ ( $\mathrm{n}=6$, ES $0.09,95 \% \mathrm{CI}$ -0.06 to $\left.0.23, I^{2}=58 \%, \mathrm{p}=0.037\right), \mathrm{WLZ} / \mathrm{WHZ}(\mathrm{n}=6$, ES $0.03,95 \% \mathrm{CI}-0.05$ to $\left.0.10, I^{2}=0, \mathrm{p}=0.669\right)$ scores and no effect on LAZ/HAZ score.

In contrast, in comparison to the stimulation intervention only group, the integrated interventions group 


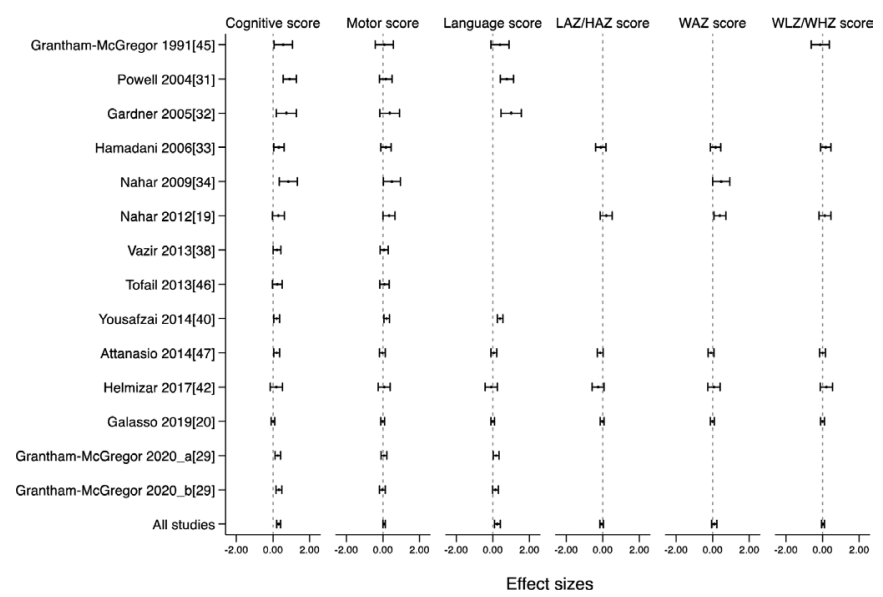

Figure 2 Effects of integrated nutrition and stimulation interventions versus standalone nutrition interventions on each outcome. Note: the size of squares is proportional to the analytical weights.

showed non-significant effects on cognitive ( $\mathrm{n}=7$, ES 0.18 , $95 \%$ CI -0.09 to $\left.0.45, I^{2}=86 \%, \mathrm{p}<0.001\right)$, motor $(\mathrm{n}=7$, ES $0.19,95 \%$ CI -0.03 to $\left.0.42, I^{2}=79 \%, p=<0.001\right)$, language ( $\mathrm{n}=6$, ES $0.06,95 \%$ CI -0.33 to $\left.0.45, I^{2}=92 \%, \mathrm{p}<0.001\right)$, WAZ ( $\mathrm{n}=4$, ES $0.02,95 \%$ CI -0.09 to $\left.0.14, I^{2}=0, \mathrm{p}=0.780\right)$ and WLZ/WHZ (n=4, ES $0.06,95 \% \mathrm{CI}-0.06$ to $0.19, I^{2}=0$, $\mathrm{p}=0.911$ ) scores and no effect on LAZ/HAZ score.

\section{Subgroup analyses of pooled ESs by intervention characteristics}

Online supplemental table 6 describes the results of subgroup analyses of integrated interventions versus usual care, by four intervention characteristics: delivery strategy, number of BCTs, intervention intensity and personnel delivering the intervention. Online supplemental table 6 also includes $\mathrm{p}$ values corresponding to the test of subgroup differences for developmental outcomes. We did not conduct a test of subgroup differences for any growth outcomes because overall ESs were not significant.

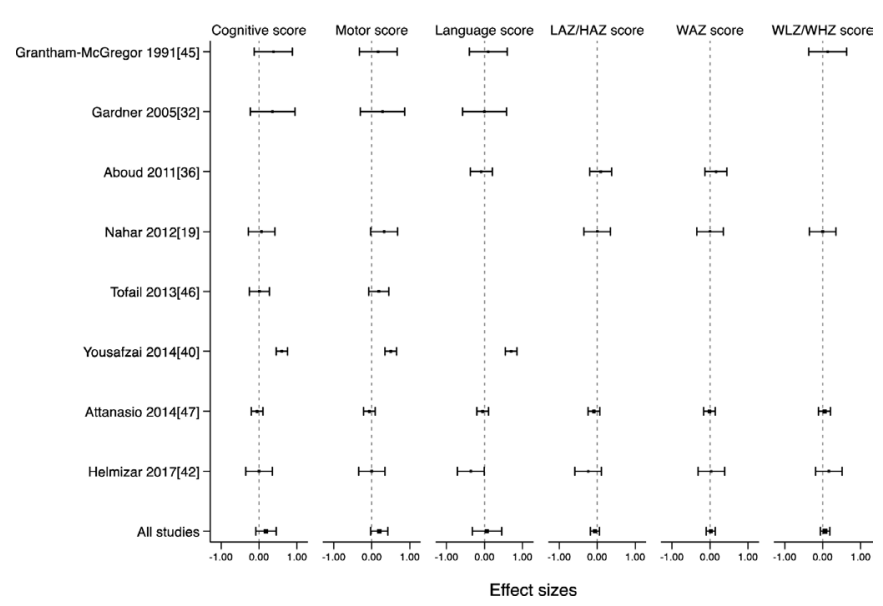

Figure 3 Effects of integrated nutrition and stimulation interventions versus standalone stimulation interventions on each outcome. Note: the size of squares is proportional to the analytical weights.
Delivery strategy: Integrated interventions that included both home visits and group sessions had a positive effect on all developmental outcomes (3-5 studies; ES range: 0.35 to 0.48 ). Similarly, integrated interventions with individual visits were found to have a significant positive effect on cognitive ( $\mathrm{n}=9$, ES $0.40,95 \% \mathrm{CI}$ 0.21 to 0.59$)$ and language ( $\mathrm{n}=5$, ES $0.20,95 \%$ CI 0.03 to 0.37 ) but not motor outcomes. Group sessions alone had non-significant effects on developmental outcomes (3 to 4 studies; ES range: 0.55 to 0.92 ). There were no subgroup differences in any developmental outcomes. Heterogeneity remained high and significant.

BCTs: Interventions incorporating three or more BCTs had a positive effect on all three developmental outcomes (10-12 studies; ES range: 0.38 to 0.62 ). The pooled effect of interventions using less than three BCTs was moderate for cognitive outcome ( $\mathrm{n}=5$, ES $0.27,95 \%$ CI 0.03 to 0.50 ) and not significant for motor and language outcomes. The subgroup differences in ESs were not significant. Heterogeneity was high and significant for all developmental outcomes.

Intensity:The interventions with a duration of $\geq 12$ months and $\geq 4$ average sessions per month had a positive effect on all developmental outcomes (7-10 studies; ES range: 0.15 to 0.53 ). Similarly, interventions with a duration of $<12$ months had a significant positive effect on cognitive and motor ( 7 and 4 studies; ESs 0.52 and 0.35 , respectively) but not on language outcomes. Interventions with $<4$ average sessions per month had a significant positive effect on cognitive outcomes only ( $\mathrm{n}=7$, ES 0.58 , $95 \%$ CI $0.12,1.05$ ). There were no significant subgroup differences in ESs. Heterogeneity was observed for all developmental outcomes and was significant.

Personnel: Interventions delivered by paraprofessionals had positive effects for all developmental outcomes (7-8 studies; ES range: 0.18 to 0.44 ). Similarly, interventions delivered by community volunteers had positive effects for all three developmental outcomes (4-5; ES range: 0.13 to 0.34 ). The pooled effect for the cognitive outcome was positive for interventions delivered by professionals only and was not significant when delivered by both volunteers and paraprofessionals together. The ES was significantly greater for interventions delivered by professionals for cognitive outcome (mean ES diff $=0.99$, $95 \%$ CI 0.38 to 1.59 , $\mathrm{p}=0.004$ ) compared with paraprofessionals. Significant heterogeneity was observed.

\section{DISCUSSION}

This systematic review and meta-analysis assessed the effects of integrated nutrition and stimulation interventions on both growth and developmental outcomes in children under 5 years, first overall, and then considering four intervention characteristics, including delivery strategy, BCTs, intensity and personnel. Our findings suggest that, in LMICs, integrated interventions tested to date produced better results in cognitive, motor, and language outcomes than usual care or standalone 
nutrition interventions, but they had no effects on growth outcomes. The effects of integrated interventions on developmental outcomes were non-significant compared with standalone stimulation interventions. These findings are consistent with previous systematic reviews that have highlighted that the effect of integrated nutrition and stimulation interventions on developmental outcomes is greater than those of standalone nutrition interventions. ${ }^{31011}$ We observed considerable heterogeneity in effects on developmental outcomes, which could not be fully elucidated through subgroup analyses. The greatest benefits of integrated interventions accrue to undernourished children, which echoes findings from a study in Bangladesh that showed significant benefits of stimulation intervention among undernourished children. ${ }^{33}$ Lastly, there were no negative consequences of integrated interventions on children's nutritional or developmental outcomes.

Existing evidence suggests that interventions providing both macronutrients and micronutrients supplementation have the largest effects on LAZ/HAZ score, ${ }^{11}$ but interventions providing only single or multiple micronutrient or nutrition education alone tend to have only small or no effects. ${ }^{50}{ }^{51}$ In our review, only two integrated interventions provided children with a known effective strategy, that is, both macronutrients and micronutrients supplementation, ${ }^{30}{ }^{37}$ which might explain the lack of significant effects on LAZ/HAZ score. Further, nine out of 20 trials in the meta-analysis were conducted in food insecure settings with high baseline levels of child undernutrition, and in which supplementation, health service strengthening and nutrition-sensitive actions would be required for any substantial gains in any growth outcomes. ${ }^{5152}$

We observed large heterogeneity of effects on all three developmental outcomes, as well as, in the intervention context, nutrition components and their characteristics, which makes the interpretation of the findings challenging. This substantial heterogeneity was highlighted by the authors of a previous review ${ }^{10}$ and a recent meta-analysis, ${ }^{7}$ emphasising the diversity in the field of early childhood interventions in general. In our review, heterogeneity remained significant in all subgroup analyses except in one analysis by nutrition components, which only included three studies. Participant characteristics may be a potential source of heterogeneity. We did not conduct subgroup analyses by child's age because the age at enrolment and assessment varied greatly, and the latter was not reported in all studies. While three trials were deemed to have a low risk of bias, most trials did not adequately report allocation concealment, blinding, and there were concerns about selective outcome reporting. Removal of the three trials included in the meta-analysis with the highest risk of bias ${ }^{45-47}$ did not reduce the heterogeneity, suggesting ESs may not have been influenced by trials' quality.

We sought to understand how four key intervention characteristics (delivery strategy, BCTs, intensity and personnel) might be associated with effects. There were no marked differences in ESs by delivery strategy. In 2015, a systematic review found that stimulation delivered through group sessions with some home visits by dedicated paraprofessionals had a moderate effect $(n=7$, ES $0.59,95 \%$ CI 0.50 to 0.68 ) on children's cognitive score. ${ }^{6}$ The advantages of using combined home visits and group session strategies compared with home visiting alone are that interventions are less labour intensive, may reduce contact hours, encourage peer support and have a potential to modify the norms for caregiving practices. ${ }^{6}$ However, the feasibility of combining home visiting and group-based strategies to deliver integrated interventions requires further investigation.

When considering BCTs, Aboud and Yousafzai suggested that interventions with more than two BCTs, particularly media for information sharing (posters, cards or brochures), problem-solving strategies and performances (demonstration and practice of play and communication), are effective in improving developmental outcomes. ${ }^{6}$ However, most studies included did not report whether or how they used theory in the development of interventions and the selection of BCTs. Theoretical foundations encourage rigorous intervention design, elucidating the proposed mechanisms through which an intervention is hypothesised to change behaviour. ${ }^{53}$ Further prioritisation of theory-informed BCTs could facilitate efforts to enhance and scale-up effective integrated interventions. ${ }^{54}$

We did not find subgroup differences in ESs by intervention intensity, which resonates with findings from Aboud and Yousafzai, who did not find any association between developmental outcomes and contact hours. ${ }^{6}$ Other studies suggest that high-intensity interventions are likely to have positive effects on developmental outcomes. For example, Powell and Grantham-McGregor found that children who received stimulation through weekly visits had better outcomes than those who had fortnightly visits. ${ }^{55}$ Similarly, in Bolivia and Philippines, effects on child development were stronger for children exposed to the interventions for longer (seven or more and at least 17 months, respectively). ${ }^{56} 57$ The robustness of these findings concerning intervention characteristics should be explored in future studies using alternative cut-off points.

We found little evidence of differences in cognitive outcome by the type of personnel delivering the interventions. However, as only two interventions were delivered by professionals, this finding is inconclusive. The existing evidence highlights that delivery of maternal and child health interventions by paraprofessionals such as Community Health Workers (CHWs) is often effective in LMICs. ${ }^{58}$ Two trials that tested integrating stimulation interventions into existing nutrition services reported promising results. ${ }^{28} 40$ However, CHWs' existing work burden must be considered when integrating interventions within existing services. For instance, a study in Brazil found that turnover was higher among CHWs in 
a parenting programme due to increased workload. ${ }^{59}$ Alternative strategies, such as increasing the number of existing CHWs or creating a new cadre of staff, can be considered. Moreover, the knowledge and skills of personnel, supervision support and their relationships with caregivers and children are critical for a successful intervention, yet these aspects are often inadequately reported. ${ }^{1360} 61$ Further efforts are needed to assess competency gaps among personnel delivering integrated interventions and map the adequacy and continuity of their training and supervision.

Our review has several limitations. We included studies published in peer-reviewed journals and in English only. Therefore, our search might not have captured all potentially relevant studies with negative results. Similarly, we could not use all studies with growth outcomes because they were not extractable (11 studies); this reduced the power of our analyses. However, we did not observe any indication of publication bias in funnel plots and Egger tests for any outcome except WAZ. Given the effect on the WAZ score was not significant, the risk of reporting bias appears to be low. To further reduce potential reporting bias, we contacted nine authors where data were not extractable and received data from three authors. We did not include studies that reported only growth or developmental outcomes, but only two studies were excluded based on this criterion. ${ }^{62}{ }^{63}$ We did not report effects on socioemotional development, a critical aspect of child development, as only three studies reported socioemotional outcome and did so differently. ${ }^{20} 2943$ Although we explored possible sources of heterogeneity by studylevel characteristics, there were still notable differences that could not be accounted for, such as participants' age at enrolment/assessment, intervention characteristics (curriculum components, training and supervision of personnel, and participants' adherence to the intervention). Moreover, we conducted many subtests $(n=30)$ with a small number of studies in each subgroup to explore intervention characteristics related to the outcome effects, which increased the risk of Type I error. It is also possible that some of our analyses were underpowered and with insufficient precision to guide decision-making. While the integrated interventions had a greater effect on cognitive and language outcomes in undernourished children than in adequately nourished children, there was significant unexplained heterogeneity within these groups. Therefore, these findings should be interpreted cautiously as individual trial results are inconsistent. Finally, none of the trials included in the review reported characteristics of integrated interventions using standard guidelines uniformly, except one,${ }^{26}{ }^{40}$ making it challenging to map the intervention components accurately.

Integrated interventions can be considered as part of a comprehensive set of actions to improve nurturing care, even if they do not yield improvements in growth on their own within the limited timescale of most trials. The high heterogeneity found among trials emphasises the need for additional studies to assess the effectiveness of integrated interventions, such as follow-up studies of trials to examine the sustainability of effects, as well as process evaluations and implementation research to investigate barriers and enablers to implementation and positive effects. Moreover, there is a need for costeffectiveness evaluations to identify the most effective integrated intervention strategies for scale up. Finally, few studies have reported intervention characteristics in a standardised manner; this needs to be improved to strengthen the evidence base.

\section{CONCLUSIONS}

Our findings confirm that integrated nutrition and stimulation interventions have positive but not synergistic effects on developmental outcomes when compared with standalone nutrition and stimulation interventions. We were unable to determine which component of the integrated interventions was associated with significant positive ES for developmental outcomes. Our findings suggest that programme developers and policy-makers should consider integrated interventions and support implementation research to better understand which interventions characteristics lead to positive outcomes and inform scale up.

\section{Author affiliations}

${ }^{1}$ School of Health Sciences, Western Sydney University, Penrith South, New South Wales, Australia

${ }^{2}$ Institute for Global Health, University College London, London, UK

${ }^{3}$ School of Population Health, University of New South Wales, Sydney, New South Wales, Australia

${ }^{4}$ Research and Development, Australian Red Cross Lifeblood New South Wales and Australian Capital Territory, Alexandria, New South Wales, Australia

Twitter Sophiya Dulal @DulalSophiya and Audrey Prost @audreyprost2

Acknowledgements We thank Ms Katrina Chaudhary (Librarian at Western Sydney University) to support the development of our search strategy and for conducting the database search and Mr Paul Fahey (Statistician at Western Sydney University) for his guidance and inputs in the meta-analysis. We also thank the authors who responded to our emails and provided data.

Contributors SD, AP and DM conceived the original idea. SD designed the study protocol with inputs from DM, AP, NS, and SK. SD conducted the database search. SD and DM finalised the choice of articles included in the review. SD, AP, NS and DM assessed the risk of bias. SD adn SK extracted data for the meta-analysis and conducted the analyses. SD wrote the first draft. All authors contributed to the interpretation and critical revision of the manuscript. All authors read and approved the final manuscript for submission.

Funding The authors have not declared a specific grant for this research from any funding agency in the public, commercial or not-for-profit sectors.

Competing interests None declared.

Patient consent for publication Not required.

Provenance and peer review Not commissioned; externally peer reviewed.

Data availability statement № additional data are available.

Supplemental material This content has been supplied by the author(s). It has not been vetted by BMJ Publishing Group Limited (BMJ) and may not have been peer-reviewed. Any opinions or recommendations discussed are solely those of the author(s) and are not endorsed by BMJ. BMJ disclaims all liability and responsibility arising from any reliance placed on the content. Where the content includes any translated material, BMJ does not warrant the accuracy and reliability of the translations (including but not limited to local regulations, clinical guidelines, terminology, drug names and drug dosages), and is not responsible for any error and/or omissions arising from translation and adaptation or otherwise. 
Open access This is an open access article distributed in accordance with the Creative Commons Attribution Non Commercial (CC BY-NC 4.0) license, which permits others to distribute, remix, adapt, build upon this work non-commercially, and license their derivative works on different terms, provided the original work is properly cited, appropriate credit is given, any changes made indicated, and the use is non-commercial. See: http://creativecommons.org/licenses/by-nc/4.0/.

ORCID iD

Sophiya Dulal http://orcid.org/0000-0002-2244-613X

\section{REFERENCES}

1 Black MM, Walker SP, Fernald LCH, et al. Early childhood development coming of age: science through the life course. Lancet 2017;389:77-90.

2 Grantham-McGregor S, Cheung YB, Cueto S, et al. Developmental potential in the first 5 years for children in developing countries. Lancet 2007;369:60-70.

3 World Health Organization. Improving early childhood development: WHO guideline. Licence: CC BY-NC-SA 3.0 IGO. Geneva: World Health Organization, 2020.

4 Vaivada T, Gaffey MF, Bhutta ZA. Promoting early child development with interventions in health and nutrition: a systematic review. Pediatrics 2017;140.

5 Larson LM, Yousafzai AK. A meta-analysis of nutrition interventions on mental development of children under-two in low- and middleincome countries. Matern Child Nutr 2017;13:e12229.

6 Aboud FE, Yousafzai AK. Global health and development in early childhood. Annu Rev Psychol 2015;66:433-57.

7 Jeong J, Franchett EE, Ramos de Oliveira CV, et al. Parenting interventions to promote early child development in the first three years of life: a global systematic review and meta-analysis. PLoS Med 2021;18:e1003602.

8 DiGirolamo AM, Stansbery P, Lung'aho M. Advantages and challenges of integration: opportunities for integrating early childhood development and nutrition programming. Ann N Y Acad Sci 2014:1308:46-53.

9 Hurley KM, Yousafzai AK, Lopez-Boo F. Early child development and nutrition: a review of the benefits and challenges of implementing integrated interventions. Adv Nutr 2016;7:357-63.

10 Grantham-McGregor SM, Fernald LCH, Kagawa RMC, et al. Effects of integrated child development and nutrition interventions on child development and nutritional status. Ann N Y Acad Sci 2014;1308:11-32.

11 Prado EL, Larson LM, Cox K, et al. Do effects of early life interventions on linear growth correspond to effects on neurobehavioural development? A systematic review and metaanalysis. Lancet Glob Health 2019;7:e1398-413.

12 Yousafzai AK, Aboud F. Review of implementation processes for integrated nutrition and psychosocial stimulation interventions. Ann N Y Acad Sci 2014;1308:33-45.

13 Britto PR, Singh M, Dua T, et al. What implementation evidence matters: scaling-up nurturing interventions that promote early childhood development. Ann N Y Acad Sci 2018;1419:5-6.

14 Alderman $\mathrm{H}$, Fernald $\mathrm{L}$. The nexus between nutrition and early childhood development. Annu Rev Nutr 2017;37:447-76.

15 Yousafzai AK, Aboud FE, Nores M, et al. Reporting guidelines for implementation research on nurturing care interventions designed to promote early childhood development. Ann N Y Acad Sci 2018;1419:26-37.

16 Moher D, Liberati A, Tetzlaff J, et al. Preferred reporting items for systematic reviews and meta-analyses: the PRISMA statement. PLoS Med 2009;6:e1000097.

17 Higgins JPT, Sterne JAC, Savović J. A revised tool for assessing risk of bias in randomised trials in: Chandler J, McKenzie J, Boutron I, Welch V (editors). Cochrane methods. Cochrane Database of Syst Rev 2016;10.

18 Sterne JAC, Hernán MA, McAleenan A. Chapter 25: Assessing risk of bias in a non-randomised study. In: Higgins JPT, Thomas J, Chandler J, et al, eds. Cochrane Handbook for systematic reviews of interventions version 6.1 (updated September 2020). London: Cochrane, 2020.

19 Nahar B, Hossain MI, Hamadani JD, et al. Effects of a communitybased approach of food and psychosocial stimulation on growth and development of severely malnourished children in Bangladesh: a randomised trial. Eur J Clin Nutr 2012;66:701-9.

20 Galasso E, Weber AM, Stewart CP, et al. Effects of nutritional supplementation and home visiting on growth and development in young children in Madagascar: a cluster-randomised controlled trial. Lancet Glob Health 2019;7:e1257-68.

21 Higgins JPT, Thomas J, Chandler J, et al. Cochrane Handbook for systematic reviews of interventions version 6.0. London: Cochrane, 2019. www.training.cochrane.org/handbook

22 Walker SP, Powell CA, Grantham-McGregor SM, et al. Nutritional supplementation, psychosocial stimulation, and growth of stunted children: the Jamaican study. Am J Clin Nutr 1991;54:642-8.

23 Yousafzai AK, Obradović J, Rasheed MA, et al. Effects of responsive stimulation and nutrition interventions on children's development and growth at age 4 years in a disadvantaged population in Pakistan: a longitudinal follow-up of a cluster-randomised factorial effectiveness trial. Lancet Glob Health 2016;4:e548-58.

24 Rockers PC, Zanolini A, Banda B, et al. Two-Year impact of community-based health screening and parenting groups on child development in Zambia: follow-up to a cluster-randomized controlled trial. PLoS Med 2018;15:e1002555-15.

25 Atukunda P, Muhoozi GKM, van den Broek TJ, Broek TJ, et al. Child development, growth and microbiota: follow-up of a randomized education trial in Uganda. J Glob Health 2019;9:010431.

26 Yousafzai AK, Rasheed MA, Siyal S. Integration of parenting and nutrition interventions in a community health program in Pakistan: an implementation evaluation. Ann N Y Acad Sci 2018;1419:160-78.

27 Rockers PC, Fink G, Zanolini A, et al. Impact of a community-based package of interventions on child development in Zambia: a clusterrandomised controlled trial. BMJ Glob Health 2016;1:e000104.

28 Hamadani JD, Mehrin SF, Tofail F, et al. Integrating an early childhood development programme into Bangladeshi primary healthcare services: an open-label, cluster-randomised controlled trial. Lancet Glob Health 2019;7:e366-75.

29 Grantham-McGregor S, Adya A, Attanasio O, et al. Group sessions or home visits for early childhood development in India: a cluster RCT. Pediatrics 2020;146. doi:10.1542/peds.2020-002725. [Epub ahead of print: 04112020$]$.

30 McKay H, Sinisterra L, McKay A, et al. Improving cognitive ability in chronically deprived children. Science 1978;200:270-8.

31 Powell C, Baker-Henningham $\mathrm{H}$, Walker S, et al. Feasibility of integrating early stimulation into primary care for undernourished Jamaican children: cluster randomised controlled trial. BMJ 2004;329:8980

32 Gardner JMM, Powell CA, Baker-Henningham H, et al. Zinc supplementation and psychosocial stimulation: effects on the development of undernourished Jamaican children. Am J Clin Nutr 2005;82:399-405.

33 Hamadani JD, Huda SN, Khatun F, et al. Psychosocial stimulation improves the development of undernourished children in rural Bangladesh. J Nutr 2006;136:2645-52.

34 Nahar B, Hamadani JD, Ahmed T, et al. Effects of psychosocial stimulation on growth and development of severely malnourished children in a nutrition unit in Bangladesh. Eur J Clin Nutr 2009;63:725-31.

35 Lozoff B, Smith JB, Clark KM, et al. Home intervention improves cognitive and social-emotional scores in iron-deficient anemic infants. Pediatrics 2010;126:e884-94.

36 Aboud FE, Akhter S. A cluster-randomized evaluation of a responsive stimulation and feeding intervention in Bangladesh. Pediatrics 2011:127:e1191-7.

37 Ogunlade AO, Kruger HS, Jerling JC, et al. Point-of-use micronutrient fortification: lessons learned in implementing a preschool-based pilot trial in South Africa. Int J Food Sci Nutr 2011;62:1-16.

38 Vazir S, Engle P, Balakrishna N, et al. Cluster-Randomized trial on complementary and responsive feeding education to caregivers found improved dietary intake, growth and development among rural Indian toddlers. Matern Child Nutr 2013;9:99-117.

39 Aboud FE, Singla DR, Nahil MI, et al. Effectiveness of a parenting program in Bangladesh to address early childhood health, growth and development. Soc Sci Med 2013;97:250-8.

40 Yousafzai AK, Rasheed MA, Rizvi A, et al. Effect of integrated responsive stimulation and nutrition interventions in the lady health worker programme in Pakistan on child development, growth, and health outcomes: a cluster-randomised factorial effectiveness trial. Lancet 2014;384:1282-93.

41 Singla DR, Kumbakumba E, Aboud FE. Effects of a parenting intervention to address maternal psychological wellbeing and child development and growth in rural Uganda: a community-based, cluster randomised trial. Lancet Glob Health 2015;3:e458-69.

42 Helmizar H, Jalal F, Lipoeto NI, et al. Local food supplementation and psychosocial stimulation improve linear growth and cognitive development among Indonesian infants aged 6 to 9 months. Asia Pac J Clin Nutr 2017;26:97-103. 
43 Muhoozi GKM, Atukunda P, Diep LM, et al. Nutrition, hygiene, and stimulation education to improve growth, cognitive, language, and motor development among infants in Uganda: a cluster-randomized trial. Matern Child Nutr 2018;14:e12527.

44 Waber DP, Vuori-Christiansen L, Ortiz N, et al. Nutritional supplementation, maternal education, and cognitive development of infants at risk of malnutrition. Am J Clin Nutr 1981;34:807-13.

45 Grantham-McGregor SM, Powell CA, Walker SP, et al. Nutritiona supplementation, psychosocial stimulation, and mental development of stunted children: the Jamaican study. Lancet 1991;338:1-5.

46 Tofail F, Hamadani JD, Mehrin F, et al. Psychosocial stimulation benefits development in nonanemic children but not in anemic, irondeficient children. J Nutr 2013;143:885-93.

47 Attanasio OP, Fernández C, Fitzsimons EOA, et al. Using the infrastructure of a conditional cash transfer program to deliver a scalable integrated early child development program in Colombia: cluster randomized controlled trial. BMJ 2014;349:g5785.

48 Schneider N, Geiser E, Gosoniu L, et al. A combined dietary and cognitive intervention in 3-5-Year-Old children in Indonesia: a randomized controlled trial. Nutrients 2018;10:1394.

49 World Health Oganization and United Nations Children's Fund. Care for child development: improving the care for young children, 2012. Available: https://www.who.int/maternal_child_adolescent/ documents/child-healthy-growth-development/en/

50 Park JJH, Harari O, Siden E, et al. Interventions to improve linear growth during complementary feeding period for children aged 6-24 months living in low- and middle-income countries: a systematic review and network meta-analysis. Gates Open Res 2019;3:1660.

51 Dewey KG, Adu-Afarwuah S. Systematic review of the efficacy and effectiveness of complementary feeding interventions in developing countries. Matern Child Nutr 2008;4 Suppl 1:24-85.

$52 \mathrm{Li} \mathrm{Z}$, Kim R, Vollmer S, et al. Factors associated with child stunting, wasting, and underweight in 35 low- and middle-income countries. JAMA Netw Open 2020;3:e203386.

53 Breuer E, Lee L, De Silva M. Using theory of change to design and evaluate public health interventions: a systematic review. Implement Science 2016;11:1-7.
54 Glanz K, Bishop DB. The role of behavioral science theory in development and implementation of public health interventions. Annu Rev Public Health 2010;31:399-418.

55 Powell C, Grantham-McGregor S. Home visiting of varying frequency and child development. Pediatrics 1989;84:157-64.

56 Behrman JR, Cheng Y, Todd PE. Evaluating preschool programs when length of exposure to the program varies: a nonparametric approach. Rev Econ Stat 2004;86:108-32.

57 Armecin G, Behrman J, Duazo P. Early childhood development through an integrated program: evidence from the Philippines. World Bank Policy Research Working Paper 39922006 https://papers.ssrn. com/sol3/papers.cfm?abstract_id=917493

58 Gilmore B, McAuliffe E. Effectiveness of community health workers delivering preventive interventions for maternal and child health in low- and middle-income countries: a systematic review. BMC Public Health 2013;13:847.

59 Smith JA, Baker-Henningham H, Brentani A, et al. Implementation of reach up early childhood parenting program: acceptability, appropriateness, and feasibility in Brazil and Zimbabwe. Ann NY Acad Sci 2018;1419:120-40.

60 Aboud FE, Prado EL. Measuring the implementation of early childhood development programs. Ann N Y Acad Sci 2018;1419:249-63.

61 Shankar AV, Asrilla Z, Kadha JK, et al. Programmatic effects of a large-scale Multiple-Micronutrient supplementation trial in Indonesia: using community facilitators as intermediaries for behavior change. Food Nutr Bull 2009;30:S207-14.

62 Cremer HD, Flórez A, de Navarro L, et al. Influence of food supplementation and/or psychological stimulation on mental development. Giessen-Harvard-ICBF project. Nutr Metab 1977;21 Suppl 1:231-4.

63 Super CM, Herrera MG, Mora JO. Long-Term effects of food supplementation and psychosocial intervention on the physical growth of Colombian infants at risk of malnutrition. Child Dev 1990;61:29-49. 